\title{
Separation of Seven Residues of Fluoroquinolones from Fish Samples using Solid Phase Microextraction and Electrophoresis and their detection by Electrochemiluminescence method
}

\author{
Fuxiu Yang ${ }^{1}$, Wenjuan Zhang ${ }^{1}$, Chunxiu $G u^{1,2, *}$, Jichao $X u^{3, *}$, Kaowen $Z h o u^{1,2, *}$ \\ ${ }^{1}$ Biochemical Engineering College, Beijing Union University, Beijing 100023, China \\ ${ }^{2}$ Beijing Key Laboratory of Biomass Waste Resource Utilization, Beijing 100023, China \\ ${ }^{3}$ Qingdao Institute for Food and Drug Control, Qingdao 266071, China \\ *E-mail: zhoukaowen@ buu.edu.cn, 20087067@buu.edu.cn, 13515320886@163.com
}

doi: $10.20964 / 2020.09 .41$

Received: 5 May 2020 / Accepted: 3 July 2020 / Published: 10 August 2020

\begin{abstract}
A new method for the simultaneous determination of 7 fluoroquinolones (FQs) in fish was established based on purifing and enriching by solid phase microextraction, separating by capillary electrophoresis (CE) and detecting by column end electrochemiluminescence. The effects of $\mathrm{pH}$ value, extraction time, extraction temperature, ionic strength and eluate type on the extraction efficiency of 7 FQs were investigated. The effects of buffer additives and separation voltage on the separation efficiency of 7 FQs were investigated. The best purification and enrichment parameters of $10.0 \mathrm{ml}$ extraction solution made from $2.0 \mathrm{~g}$ fish sample are: $\mathrm{pH}$ value of extraction system is 7 , extraction time is $40 \mathrm{~min}$, extraction temperature is $50{ }^{\circ} \mathrm{C}$, addition of $\mathrm{NaCl}$ is $2.0 \mathrm{~g}$, and eluate is $2.0 \mathrm{ml}$ methanol (containing $5 \%$ formic acid). The separation solution of $\mathrm{CE}$ is $0.02 \mathrm{~mol} / \mathrm{L}$ phosphate buffer solution $(\mathrm{pH}=6$, containing $18 \%$ cyclodextrin), and the separation voltage is $20 \mathrm{kV}$. All the 7 FQs have good linear relationship. Their detection limits were $0.4-0.8 \mu \mathrm{g} / \mathrm{L}$. The recovery of fish samples was $89.2 \%-110.4 \%$. 4 FQs were detected in two fish samples. This method has the advantages of small matrix effect, high sensitivity, simplicity and accuracy. It can be used for the detection of FQs in other fish or meat.
\end{abstract}

Keywords: Fluoroquinolones, Fish, Solid phase microextraction, Capillary electrophoresis, Electrochemiluminescence

\section{FULL TEXT}

(C) 2020 The Authors. Published by ESG (www.electrochemsci.org). This article is an open access article distributed under the terms and conditions of the Creative Commons Attribution license (http://creativecommons.org/licenses/by/4.0/). 